\title{
Swiss military drones and the border space: a critical study of the surveillance exercised by border guards
}

\author{
Silvana Pedrozo \\ Institute of Geography, University of Neuchâtel, Neuchâtel, Switzerland \\ Correspondence to: Silvana Pedrozo (silvana.pedrozo@unine.ch)
}

Received: 26 May 2016 - Revised: 9 December 2016 - Accepted: 20 January 2017 - Published: 24 February 2017

\begin{abstract}
This paper focuses on the Swiss border guard's relationship with the border space since the use of military drone systems (ADS-95 Ranger) for surveillance missions. Firstly, the paper highlights how the use of these flying devices both facilitates and limits the acquisition of new knowledge by the border guards. It then explores the way in which the fundamentally mobile and flexible nature of this technology also gives rise to new surveillance practices and identification controls. We show that these changes influence the border guard's relationship with the border. To achieve this, our analysis is based on empirical data obtained from semistructured interviews with key players in the field, action maps and field observation carried out during a "drone engagement" in September 2014. One major question therefore guides this study: how do military drone systems - by way of the new knowledge and practices they generate - influence relationships in the border space?
\end{abstract}

\section{Introduction}

Today, many surveillance technologies (video surveillance, radars, satellites) are used by public authorities to monitor and control the national territory. Military drones form part of these technologies and have become a key tool in the surveillance and identification systems that are being implemented globally. Switzerland, like many other states, has equipped itself with this fundamentally mobile and flexible aerial technology (Klauser and Pedrozo, 2015), allowing it to fly over geostrategic spaces such as the Franco-Swiss border space. The use of these drones generates new knowledge and influences surveillance practices and identification controls. Indeed, as Klauser (2012b) points out, surveillance systems need such input as they do not function or produce anything in and of themselves.

This paper draws upon a growing interdisciplinary literature that explores the complex spatialities of surveillance relating to the control and management of different types of circulations and flows (Amoore et al., 2002; Klauser, 2013). More specifically, it draws on and contributes to work examining how - in the big data era - new technologies (biometrics, chips, sensors, Internet activities) are used to control and manage mobility in border spaces (Amoore, 2006; Côté-Boucher, 2010; Wood and Graham, 2006). As this work highlights, the use of technology responds to the need in our globalised era to develop circulations of people, objects and wealth while preventing the risks associated therewith (Widmer et al., 2014). The need to monitor, manage and optimise day-to-day mobility through the production and analysis of numerical data relating to the localisation and displacement of flows opens up new possibilities for tracing these mobilities as well as for exploiting and storing data. This observation is particularly salient in the case of contemporary borders, whose spaces are increasingly difficult to monitor and secure because they are "everywhere" (Lyon, 2005). Amoore et al. (2002) describe such borders as mobile and ubiquitous, which could also be a description of their surveillance (Andrejevic, 2012) as well as of their systems of control, filtering and customs, which are becoming more and more widely practised (Szary and Giraut, 2015).

Drone surveillance of the Swiss border spaces is a special case insofar as it differs from the situation in the United States (Wall and Monahan, 2011), Israel (Zureik, 2011) or Brazil (Muggah and Diniz, 2013), where these machines have higher specifications and are often armed. In Switzerland, the current military drones do not have the capability to be armed or deployed in conflict zones. Rather, they respond to a need to secure the border spaces in the face of 
large migratory flows and to monitor nearby residential and industrial watch-making areas (2014 field observation). This singular context raises interesting questions in terms of the new knowledge and surveillance practices exercised by the border guards and Swiss air forces. On the basis of this observation, the aim of this paper is to stimulate reflection on the deployment of Swiss military drones. More specifically, we will attempt to answer the following question: how does the military drone system - by way of the new knowledge and practices they generate - influence the relationship between the border guards and the border space? On occasion, this paper will also refer to future Swiss military drones which will be in use by 2019, because, over and above the vigorous debate that they provoke, the use thereof implies changes in terms of surveillance. We will therefore share some reflections on this imminent upheaval.

\section{Theoretical framework}

The theoretical framework chosen to approach our problematic is based on the relational approach developed by Claude Raffestin (1986). This approach revolves around the notion of territoriality, from which it builds a reflection on the relationship between humans and the world. Territoriality is thus defined as the set of relationships we maintain with "exteriority" and "otherness", with the help of mediators (instruments, techniques, ideas, etc.), in order to ensure our autonomy, taking into account the resources available in the environment in which we live (Raffestin, 1990). Taking relationships with exteriority into account allows us to analyse the relationships that border guards maintain with the border space, which is considered here to be a frontier territory, in the sense that it is used daily by its actors and is subject to (re)appropriation (Raffestin and Bresso, 1982). Otherness, meanwhile, is our gateway to examining the relationships that the border guards establish with the other actors in charge of the security of the territory. In his work on human territoriality, Claude Raffestin points out how important mediators are, because any relationship to the physical or human environment presupposes a form of mediation: "for example knowledge, language, social rules, technical instruments and human senses can be seen as mediators, in that they affect social and spatial relationships crucially" (Raffestin, 1984 cited by Klauser, 2007:175). Instruments and codes mediate the relationship between the subject and the object and condition the way we make use of space (Klauser, 2012a). The relationships thus modulate a territory that is "in perpetual evolution, in perpetual transformation" (Raffestin, 1982:168). We therefore consider the drone to be a "new" mediator that both makes possible and limits human actions, which are constantly renegotiated and updated. We then demonstrate that technology is the result of interaction between human and object, that it has mediating effects and that it acts on what surrounds and transforms it.
Analysing the influence of this "new" mediator, therefore, leads to exploring the knowledge and sociospatial practices of the environment under study since, according to Raffestin (1986), geographers should endeavour to explain the knowledge of practices and the knowledge that people have of space in order to understand how human groups occupy, exploit and model space and thus transform it into territory. We will therefore endeavour to clarify the knowledge that the drone system generates during a mission in order to understand how its use influences the relationships that border guards maintain with the spaces in which they operate.

We also base our thesis on the Raffestinian concept of the border, which he develops in his outline theory of the limit (Raffestin, 1986). For Raffestin, the border is a specific type of limit, which he defines as "a subset of the set of limits". $\mathrm{He}$ attributes it as being fundamentally relational and nonarbitrary in nature, as it is realised only by the relationships that an individual or collective subject has with a space. Its most prominent function here is that of control, which, to borrow his words, performs "the surveillance of people and goods at the time of the crossing of the border: control of migratory movements, control of capital and goods" (Raffestin, 1986:13). By analysing the surveillance and control systems in place over the Swiss border space, we will examine the components of security practices, especially in terms of mobility and flexibility of surveillance, linking them to the notion of the "border line" (Raffestin, 1986).

In sum, the Raffestinian approach is relevant to us because he proposes a mediation-centred and relational posture which permits us to adopt a geographical approach on the drone problematic. Thereby, he offers conceptual tools to undertake a reflection on the role of mediators and provides the basis to analyse how drone systems redefine knowledge and sociospatial practices. This way, we will be able to analyse how the use of a "new" mediator alters the relationships that an actor has with a space. To do this, we will structure our analysis on the basis of this theoretical contribution, which suggests exploring the knowledge of the actors if we want to grasp the territorial reality arising from the relationship that a subject (individual or collective) establishes with the space (Raffestin, 1986). Thus, we will first examine how the use of military drones makes possible and limits the acquisition of new knowledge from the areas under surveillance. Secondly, we will analyse how this mobile and flexible technology also influences surveillance and identification practices. In the concluding section, we will summarise the key analytical elements and answer the research question presented at the beginning of this paper.

\section{Field of study and methodology}

This paper is based on a field study carried out in 2014 by the border guards and Swiss Air Force. It mainly concerns the border region of Vaud and Geneva, as well as certain ar- 
eas within the interior of the territory, since the drone systems take off from the Payerne military airfield (canton of Fribourg). The map shown below delineates (in red) the main target area for the surveillance. It pinpoints the spatial distribution of the places (customs posts, military air base and intervention areas) and the actors (border guards and military) interviewed and involved in a "drone engagement". It should be noted that the term "drone engagement" refers to any mission in which the Swiss military drone system is used, for tasks such as surveillance, observation and reconnaissance.

The ADS-95 Ranger drone system has been used by the Air Force since 2001. According to our interviews, they collaborate about 10 times a year with the border guards of this region in drone engagements whose main aim is surveillance, although this is not the only objective. They also contribute to "the surveillance of part of the national border, part of the foreign territory near the border and the main communication channels, as well as surveillance at conferences and in cases of forest fires and hijacked aircraft; [drones also contribute to] damage inventories after natural disasters, searches for hidden deposits and refuges, the surveillance of congested areas as part of traffic control, and vehicle chases" (Swiss Confederation 2012). In September 2014, we had the opportunity to participate in a drone engagement during a night mission that took place in three phases. The first is a phase that we have called "pre-engagement". This took the form of a 20 min round table that gathered together (remotely, via teleconference) all stakeholders in the mission. The purpose of this phase was to discuss the objectives of the mission and the potential problems. The second phase - the engagement phase - began once the ADS-95 was in flight. In our case, this phase lasted around $5 \mathrm{~h}$. The third, post-engagement phase, included a debrief and allowed the mission to be brought to a close via a final video conference. During this drone engagement we applied three types of qualitative methods, from which comes a portion of the empirical data drawn on in this paper.

The main method used was that of semi-structured interviews. We conducted a dozen interviews with key players, including an engagement and planning leader for the drone engagements, five border guards, a five-man field team and two military drone pilots. The overrepresentation of border guards interviewed in relation to military personnel is explained by the fact that there were more engaged border guards than military personnel involved in the mission. It is also important to mention that other interviews were carried out at different times of the year (between April and October 2014) and at several sites (Payerne military airfield, Cure customs office and the Federal Customs Administration) in order to limit methodological biases.

The second method was that of field observation, which lasted around $9 \mathrm{~h}$. During this period, we were able to collect important data from documents provided by our contacts. This included photographs, action maps and video recordings. However, due to the sensitivity of this field of study and the confidentiality of the material, it cannot be drawn on in its entirety for this paper.

It should also be pointed out that the collected maps will not be analysed in detail but will be used illustratively in order to outline and support our arguments. We consider them to be mediators of the discourse of our contacts, helping us to understand the reasons and the choices behind the spaces targeted by the mission.

Finally, we collected and analysed factual information from the media and official documents from the border guards and the Swiss Air Force. The latter are useful for understanding the general and internal organisation of a drone mission. They offer, for example, graphs and simplified spatial schematisation, which we have redesigned in an attempt to describe this complex field of study.

\section{Analysis}

\subsection{The ADS-95 drone system: a catalyst of new knowledge?}

The drone engagements along the Swiss borders are part of a civil-military agenda aimed at better managing, controlling and securing its border spaces. The main objective of the drone system is to optimise surveillance and identification controls. Surveillance should be understood as the observation, monitoring and examination of a person's behaviour, travel, itineraries and relationships, as well as the collection and processing of information related to these actors. Identification controls, in contrast, include summonses, testimonies, certification of identity, and recognition within a group or community by means of relatively stable criteria (Ceyhan, 2006).

In the first analytical section, we will examine the extent to which the ADS-95 drone system enables access to new knowledge. Secondly, we will put the "contributions" of this technology into perspective by focusing on what limits the acquisition of knowledge and hinders the accumulation thereof.

The second analytical section will examine what this knowledge generates in terms of surveillance practices and identification controls. We will then assess how the mobility of the drone acts as an extension of the border line's surveillance and identification controls within the territory, and we will demonstrate that the flexibility of this equipment tends to transform these practices by making them more spontaneous and "tailor-made".

\subsubsection{The quest for (new) knowledge: acquiring data}

The role of information technology is vital in constructing knowledge (Coeckelbergh, 2013:93). Drones - as well as radar, GPS and satellites - offer surveillance of an unprecedented magnitude, giving access to an ever-wider and more exhaustive mass of information. The gaze from above on 


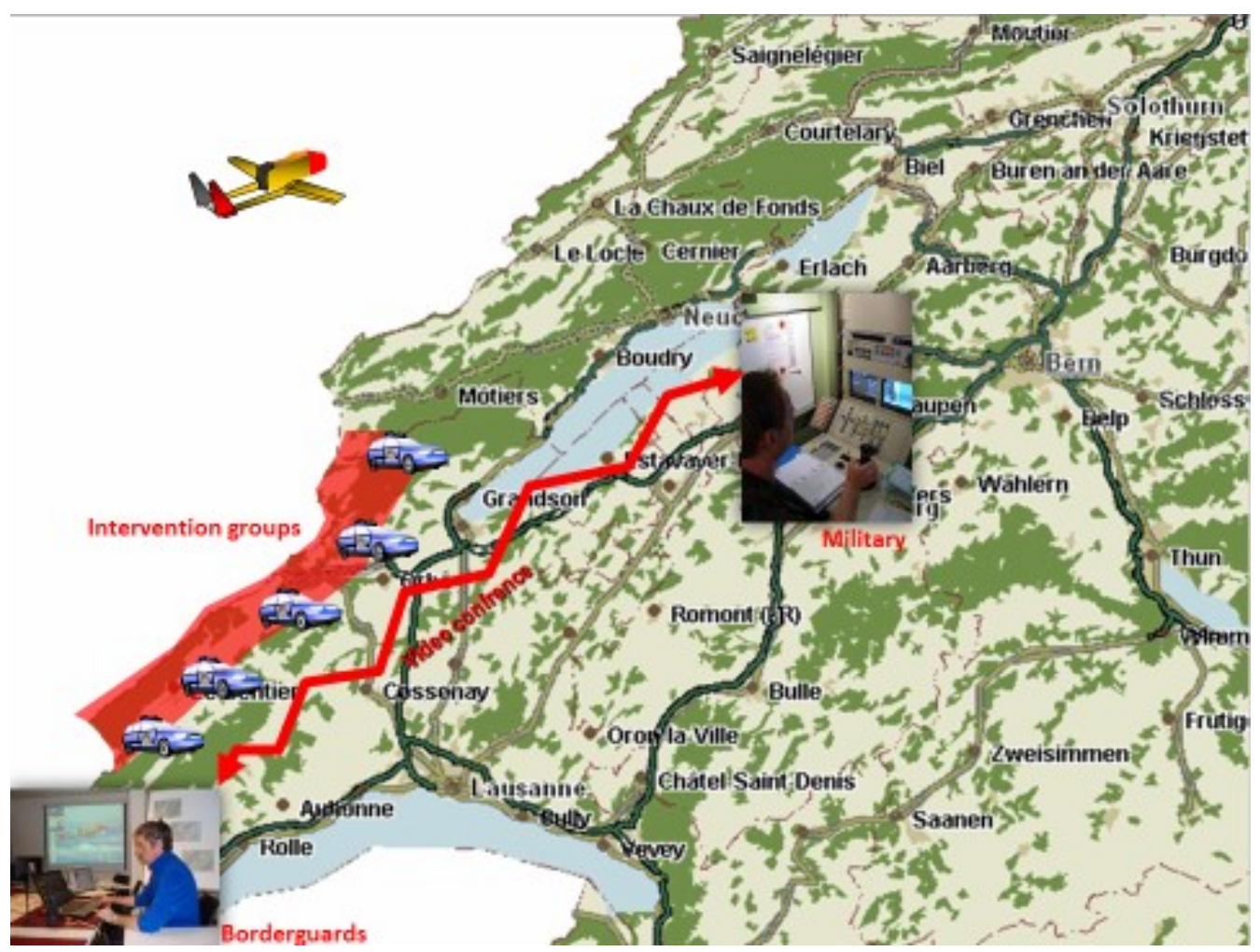

Figure 1. Visual representation of the location of the actors Plan drafted by the border guards, amended by Silvana Pedrozo (2016a).

contemporary society in order to monitor its subjects and objects is becoming commonplace and plays a role in the use of ever more efficient technologies in the hope of maximising data acquisition. The Swiss border guards understand this, which is why they have been using drone systems in the Swiss border space for more than 15 years. Their purpose is simple:

It [the drone] is used for surveillance, intelligence gathering or verification of information. Our objective is to have a better knowledge of what to look for and where to look. As it is, certain areas are better known, sometimes difficult to access, and we may or may not be able to send field officers, depending on the case. ... Having the maximum possible information on the terrain is of fundamental importance to us ... (Head of drone engagement, border guard, 23 September 2014).

Our interviewee thus considers the drone to be a valuable source of information, insofar as it helps him to know what to monitor and in which areas. This echoes the thesis of Wall and Monahan (2011:243) that "a primary goal of drone surveillance is to collect overhead imagery that might prove tactically useful". While previously, information was primarily sourced from computer databases and other security actors (police, fire department or hospitals), the use of drones appears to be a "new" mediator which increases the infor- mation available about individuals (who) and objects (what) which "become things to track, monitor, apprehend" (Wall and Monahan, 2011:246) in certain target spaces (where) via surveillance.

The use of drones thus contributes to the acquisition of new knowledge including, in particular, the consideration of a new spatial capital which we envisage as the "set of resources accumulated by an actor to allow him to take advantage, depending on his strategy, of the use of the spatial dimension of society" (Lussault and Lévy, 2003:124). Drawing on a new spatial capital becomes a gateway to understanding the "ordinary journeys, leisure mobilities and migratory mobilities that construct an experience of a space, a knowledge of the world, familiarity with places and their charms and attractions, their accessibility, and the relationships that can be developed there" (Loudiyi et al., 2004:7). Here, the acquisition of this new spatial capital is promoted by devices which allow the collection of more precise data, remotely and in real time. The border guards can then locate and track individuals, groups or vehicles, extracting data about their mobilities, their behaviours and their interests and their reasons for being in a place when an identification control is carried out.

The acquisition of new knowledge is perceived positively by our interviewees. They feel it is beneficial because their security strategies are improving. Formerly confined to customs posts and their surroundings, they now have the ability 
to observe and access hard-to-reach, remote areas, as well as residential and industrial areas targeted by the mission. With increased knowledge and improved practices come a (re)appropriation of certain spaces. Convinced of these benefits, they also note that the drones transmit information that is continually updated. This consensus on the part of our interviewees may, however, be surprising given that the ADS-95 dates - as the name suggests - from the 1990s. Why is this technology still so well regarded 20 years on? According to our analysis, this is due to its ability to produce information that remains of fundamental importance and to respond to the demands of modern security policies that perceive certain mobilities as sources of danger. With its thermal and infrared cameras and sensors, the drone system offers a wealth of information with which no other technology can compete.

Currently, types of buildings and vehicles can be recognised, and people's silhouettes can also be observed thanks to the thermal sensors. Facial recognition is not possible. (Head of drone engagement, border guard, 23 September 2014).

This extract enables us to take into account what the ADS95 can make visible (or not). Thus, we know that it offers only partial recognition of the individuals and objects on the ground. Although "the modalities and technicalities of the deployed aircrafts imply the extended and redefined possibilities of vision and visualisation from above" (Klauser and Pedrozo, 2015:286), it is not possible to obtain completely exhaustive information. However, this need not shed negative light on the positive views of our interviewees. Our analysis is more nuanced and agrees with Wall and Monahan (2011:240), who state that "in practice, these surveillance systems and their agents actively interpret ambiguous information that continuously defies exact matches or clear responses". Because the technology is limited, the knowledge is still incomplete. Hence, doubts remain, giving rise to renewed identification controls by intervention groups. Waiting in position at various places within the border space and within the territory, they are ready to intervene. They also move about as requested by of the Head of Engagement who sends them to the field. From our point of view, these controls are carried out in very systematic ways and rarely result from a "real" need for verification in respect of an imminent risk. Without going into more detail on this point, let us note that this question mirrors the debates on the legitimacy of using surveillance technology (Kennedy, 2012) and interpretive biases with regard to the collected data (Kurgan, 2013).

The issue of data storage also merits discussion, as it influences knowledge and practices, particularly in terms of duration. Indeed, it is clear that the use of drones goes beyond the issue of observation and the localisation of individuals and objects, since it makes it possible to store "traces" in databases that have become new objects of power and knowledge for the holding states. In this regard, our interviewees always began by discussing the storage period for the data, such as the recordings of images and computer data, which amounts to 30 days (source: interview with a pilot, 22 September 2014). During this period, the data are retained by the Air Force, which then deletes them, unless they need to be stored for potential retrospective use.

Only those images that are necessary for debriefings, training or as evidence, for example, can be stored. The rest cannot be kept. (Drone pilot, Air Force, 23 September 2014).

Storing data in order to gain information on the moving subject therefore appears to be an issue. Can we really ensure their "definitive" deletion, when we know that the use of servers remains problematic and that technologies do not "forget" (Kitchin and Dodge, 2011)? How do we justify the need to retain images in the medium to long term? While Snowden's revelations about the activities of the National Security Agency (NSA) bear witness to the challenges of transparency, our interviewees say that the ADS-95 does not pose a risk. Three reasons are given. Firstly, the use of the Swiss military drones remains sporadic and few images are retained over the medium or long term. This is coupled with the fact that the current devices are equipped with old technology which does not allow the acquisition of "problematic" data, because the data are only partial (silhouettes and shapes) and no audio is possible. Finally, the army is subject to military security orders which should be sufficient to resolve any potential abuses. What is important to note here is that the drone engagements allow the acquisition and transmission of data in real time as well as in the longer term. Consequently, the information is also mobile and flexible from the point of view of its spatiality and its temporality and remains subject to the "goodwill" of the actors who hold it.

This first section demonstrates that the drone system is a mediator influencing the acquisition of new knowledge. Thus, the data collected transform the physical territory into visual and numerical data, creating a mass of additional information for its users. In the eyes of these users, drones appear to be a necessary technology if they want to maximise their knowledge and optimise surveillance as well as both air-based and land-based identification controls. This echoes the interests of modern states in taking over the skies by acquiring and developing new information and communication technologies (ICTs) in order to better design their security strategies and to exercise power from above (Williams, 2011; Aubout, 2011; Elden, 2013).

\subsubsection{Limited knowledge}

While the two previous sections demonstrate how a sociotechnical system such as ADS-95 makes it possible to acquire new knowledge, this observation merits qualification. Indeed, our analysis notes both technological and human factors limiting this phenomenon. 
From a technological standpoint, let us recall that the current drone system dates back to the 1990s, which restricts, in particular, its mobility and flexibility. While the majority of deployed military drones offer "total" mobility over their territory as well as a flexibility of the technological tools placed on the aircraft, this is not the case in Switzerland. For example, there is little surveillance of any mountain regions. As for the technological capabilities (cameras and sensors), they remain poor. Thus, for one reason or another, access and adaptability may be restricted to certain areas under surveillance.

Furthermore, the loud noise produced by the drones is also limiting. While drones are often described as a stealth technology (Baconnet, 2014; Zubeldia, 2012) because their pilots are unidentifiable and they are invisible to the "parties under surveillance", here they can be both seen by the naked eye and heard. Their stealth is therefore partial and calls into question the drone's ability to sneak discreetly into the airspace.

The ADS-95 is also sensitive to unfavourable weather conditions (fog, rain) to such an extent that it is used less in autumn and winter. Weather events thus affect surveillance and lead to changes in trajectory, modifying the planned surveillance areas. Climatic factors regularly lead to the abandonment of drone engagements.

Finally, above and beyond the technological limits, the drone system requires numerous collaborations in which each actor (pilot, border guard, operators, analysts, maintenance team) has a specific role and depends upon an institutional hierarchy and on strategies that distinguish it from the other actors. Thus, these various stakeholders have their "own social dynamics, but they are also embedded in a larger network of people and a political context, including senior officers, intelligence analysts, military lawyers, political actors, etc." (Coeckelbergh, 2013:93). In Switzerland, the engagement of a drone system requires a staff of about 15 people, which is high, impractical to set up and costly. This explains why the number of missions remains low, at a rate of 10 per year and per region. Currently, the Swiss Air Force has 16 drone pilots (10 militiamen and 6 army pilots) to carry out the drone missions. Using the ADS-95 more frequently would require the training and engagement of new military drone pilots and therefore new financial costs.

Although this is not the purpose of this paper, we wish to point out that the limits observed also have implications for the surveillance and identification controls in the border space. More precisely, we find that they generate inequality among the spaces under surveillance. Indeed, our analysis follows the same direction as the research by Heyman (2010) and Finn and Wright (2012), who note sociospatial inequalities arising from the use of drones. In our case, these are produced in particular by "systemic and routine attention practices and techniques" (Lyon, 2007:14) focused on certain areas (residential, industrial, abandoned, etc.) and transit routes, while other areas (mountainous, too remote or close to an airport) are avoided or even excluded from any aerial surveillance. Several factors (technical, technological, human and even meteorological) are behind this. Thus, whether this inequality is the result of human choice or is imposed by external factors, it undeniably engenders a disparity in the areas monitored and controlled by the border guards. While ADS-95 is supposed to reduce the risks generated by modernity, is it not likely to develop other risks by creating new forms of inequality and resulting in certain individuals and spaces being targeted to a greater extent?

Without claiming to provide an answer to this question, it nevertheless seems important to note that surveillance measures are set to evolve when the Swiss Air Force uses its new drones, which are capable of

... flying higher, for longer (more than 36 hours as opposed to 4 hours currently) and irrespective of whether it is day or night. ... They will be able to observe the entire territory. ... The various sensors which equip the ADS15 will be the latest generation. (Deputy Head of Communications, Air Force, December 2014).

The current limits of the ADS-95 could thus be exceeded, and access to new knowledge optimised. While greater visibility of the territory will be possible, it will be interesting to analyse how the arrival of a "new" technology fits into a preexisting surveillance system and how it influences knowledge and security practices.

Consistent with the analysis in this first section, we consider military drones to be the mediator of knowledge, which makes it possible to acquire "new" knowledge while also limiting it. Since all knowledge is always involved in practice, and any practice involves a certain knowledge the reality on which it is exercised (Blot, 2005), the following section seeks to analyse how the mobility (1) and flexibility (2) of the drone entail new surveillance practices and identification controls.

\subsection{Drone and mobility: beyond linear surveillance}

Drones are fundamentally mobile objects (Graham and Hewitt, 2013). They participate in the evolution of contemporary mobility practices promoted by new means of production, transmission and processing of spatial information to increase the visibility of the territory. Therefore, some authors assimilate them with technologies intended to track "everything that moves" (Bigo, 2011:109), to manage and control our daily mobilities (Jensen, 2016) and to monitor and control spaces such as conflict zones or border areas (Gregory, 2011; Feldman, 2011).

Many modern states have chosen to use mobile air technology to monitor the border area, to manage "the people who occupy it, who cross it, who wish to enter or leave it, and who are the intended subjects of control measures" (Deboosere and Dessouroux, 2013:4). In order to achieve their objectives, 
they scrutinise certain areas which are subject to controls. Switzerland does not escape this trend. This is illustrated by the cartographic representation in Fig. 2, which schematises part of the geostrategic areas over which the ADS-95 flew during the mission.

This map was created from a confidential map provided by the border guards. Generally, they produce it a few days before the mission and send it to the Air Force pilots a few hours before the mission. This cartographic representation is interesting because it supports one of our main results: the mobility of the drone system gives rise to surveillance and identification controls that extend from the border line (shown here in light pink), via transit routes to the interior of the territory (areas shown in blue). This analysis echoes the remarks of Raffestin, who suggests that contemporary borders can be simultaneous, in different places and times within the same territory (Raffestin, 1986). While the border guards that we interviewed carried out surveillance and controls mainly at customs posts, their areas of action expanded under the influence of new methods of observation which influence their relationships with the environment. This "extension" of practices is all the more interesting because it takes place vertically and remotely (Mitchell, 2015). While Raffestin uses two-dimensional (geometrising) concepts (points, lines, areas) to analyse territorial relationships (Villeneuve, 1982), the fact of this "new" aerial component, as imposed by the drone, transforms the relationships to space into the three dimensions generated here by a more "voluminous" surveillance of the territory. This echoes the writings which discuss the implications of the aerial dimension in the exercise of power (Adey, 2013) as well as its effects on the ground (Elden, 2013). Consequently, the aerial view will entail the (re)appropriation of (new) spaces from the air, as well as highly systematic identification controls in order to verify the reasons to explain the presence of individuals or objects.

Furthermore, this mobile device not only offers an aerial view of that which was fixed and mapped in advance but also promotes remote, real-time monitoring of movements. Rather than using a fixed surveillance system in a confined space, like a CCTV camera would (Heilmann, 2005), the border guards demonstrate their interest in using a moving device with the capacity to transmit, trace and update data. This entails changes in the way in which human and non-human activities are monitored both along the border line and within the territory. During our field observation, it was mainly vehicles and individuals considered to be suspicious that were targeted. The border guards seek to manage mobilities using data which facilitate their location and behaviour through the transmission of data. There then follows a phase in which the mobilities are evaluated, with the aim of distinguishing the good from the bad (Amilhat-Szary, 2015; Klauser, 2012b; Amoore et al., 2002). In our case, the "evaluators" of these mobilities were the Head of Engagement and the pilot, who interpreted all of the information. Many authors (Bonditti, 2005; Ceyhan, 2004, 2006) have analysed the sorting methods employed at the border. Here, it is mainly a process which results from an interpretation of the data, as "faced with the density of the flow of information to be processed, competent technicians are required to select the most useful information and to analyse it. Raw data is nothing without human added value" (Younsi, 2015:13). Thus, depending on the visual and digital data, the Head of Engagement (in consultation with the pilot) determines whether or not to send the field crews to carry out the identification controls. It is interesting to note that their decisions have never been challenged by their peers, which confirms their central and influential position with regard to surveillance and controls. As the surveillance and identification controls depend mainly on two individuals, there are therefore crucial questions to consider: what about subjectivity of interpretation and what role should it play in such activities? What are the consequences in terms of collaborations and the legitimacy of the "surveillance" practices?

We, therefore, suggest that there has been an evolution of surveillance practices and identification controls since the ADS-95 has been in use. Because of new knowledge and security practices, the controls are dispersed and no longer follow the linear and continuous form of the border but rather are carried out in places located throughout the territory. This observation echoes the writings commenting on the dotty and pixelated form of the controls (Bonditti, 2005:9) which results from the mobile surveillance of circulations of both people and objects (Graham, 2009; Bonditti, 2011; Aas, 2005; Amoore, 2006). The limits are therefore pushed back, multiplied and diffused over "new" spaces. Thus, our analysis agrees with Raffestin's remarks when he suggests that the linearity of the border is more apparent than real and that it is appreciable on maps - as illustrated above - but remains ultimately very blurred in reality (Raffestin, 1986:8).

\subsection{Drone and flexibility: spontaneous and "tailor-made" surveillance}

As we saw earlier, the drone is a mobile flying object. But it is also characterised by its ability to adapt to many contexts and users, which makes it fundamentally flexible (Blackmore, 2005; Crandall, 2015). Some authors describe it as a system which allows mobile surveillance "for greater operational flexibility" (Wall and Monahan, 2011:241). While video surveillance already enabled simultaneous surveillance thanks to its zoom capabilities and combinations of surveillance objects (Klauser et al., 2006), the use of drones multiplies the number of applications thanks to the many entities that can be placed on the device and interconnected with other technologies (Wall and Monahan, 2011; Graham and Wood, 2003; Lyon, 2006, 2007; Philippens, 2013). Cameras and sensors are therefore emerging as new surveillance tools which reduce the rigidity of surveillance and thus allow for more liquid, spontaneous and tailor-made surveillance (Bauman and Lyon, 2013). 


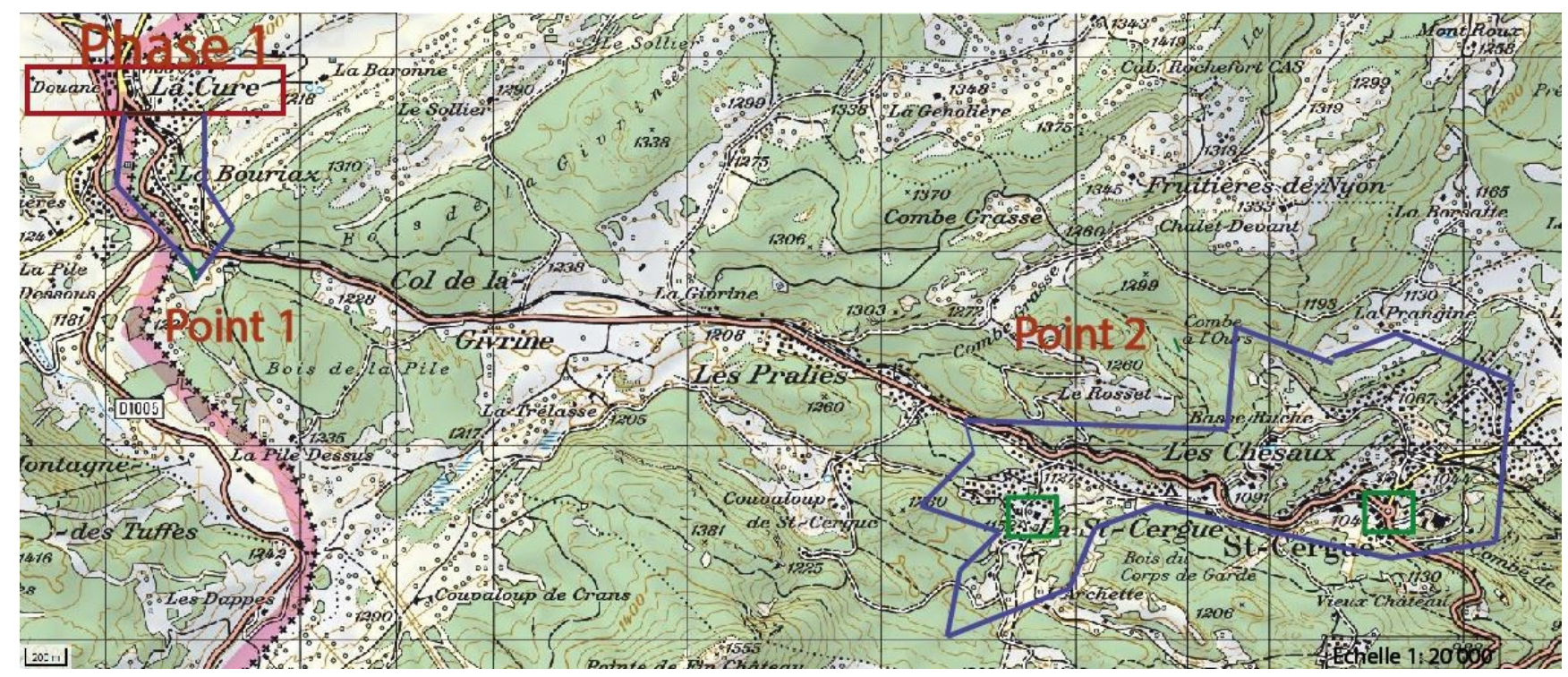

Figure 2. Reproduction of a "drone engagement" map Created by Silvana Pedrozo (2016b).

In our case study, the flexibility of surveillance and identification controls is made possible by two entities placed on the ADS-95: cameras and thermal sensors. As our interviewees attest, these elements are essential because they provide multi-directional visibility, shift to different geographic scales in seconds, and collect visual and digital data that only the drone is currently capable of transmitting. Our interviewed pilot described - in the first paragraph of his response - the appeal of this:

It is not the temperatures but rather the thermal emissions that can be spotted during infrared missions. So you can tell whether a vehicle is hot, whether it's cold, whether it's been used or not. It's very effective for spotting people and it is very useful for us.

After the question, it is always in conjunction with a situation and there needs to be a more precise and situation-specific analysis. We will say, if there are two people who walk off the roadways in a residential area, that it is obviously suspicious because it could be burglars ..., it reveals information that we assume to relate to nefarious activities. (Drone pilot, Air Force, 23 September 2014).

The first part of this quote illustrates how, by using the cameras and sensors, our actors succeed in locating and extracting data about people and objects. In addition to this response, the confidential records that we have seen show that the flexibility of the drone facilitated the arrest of migrants in disused trains, the pursuit of burglars in residential areas and the pursuit of fleeing vehicles preparing to cross the border between France and Switzerland. The ability of the drone to adapt to events makes it possible to perform flexible and, therefore, more spontaneous surveillance. Like the American Reapers, the cameras and sensors of the ADS-95 "might seem tailor made for the task of border surveillance and assisting in the apprehension of illegal aliens and drug smugglers crossing the border" (Wheeler, 2012:9). Thus, the parameters of the drone are set and adjusted depending on the data that the border guards wish to obtain (Lambeth, 2008). This is why the Swiss Air Force is seeking to maximise the flexibility of their equipment by acquiring new drone systems.

The improvements over the current ADS-95 system include: significant improvement in costutility, more flexibility in opportunities for engagement, due to its ability to be engaged in all weather conditions, significantly better autonomy in the air, fewer stations on the ground, less noise nuisance and engagements without an air escort. (Swiss Confederation, 2015 Armaments Programme).

Ultimately, the use of new machines could allow a more surreptitious, yet more continuous, surveillance of the Swiss territory. This would allow the collection of more precise information about both individuals and objects, completely rewriting the way in which surveillance is performed. This is particularly pertinent in the context of modern states' quest to go beyond regimes of "solid and heavy surveillance ... fixed on specific places, such as borders or clearly delineated physical spaces, or on previously determined individuals" (Ceyhan, 2006:5). This is clear in the second part of the drone pilot's response, which suggests a need to contextualise the information gathered. Indeed, while the rigidity and fixedness of video surveillance placed limits on the area of territory 
monitored, mobile and flexible aerial surveillance provides access to a wider environment, in real time and remotely. This makes it easier to judge a risky situation and to relay information and thus is crucial because the relaying of information involves the use of other security tools managed by other territorial security actors (police, fire department, paramedics, etc.) brought in to intervene in the field. While we consider the drone to be a mediator of knowledge and practices, it is therefore also a mediator of collaborations. In fact, it brings together both information and skills. As this pilot testifies, it leads different actors to work together in the securitisation of a space:

We work for the same cause, that is, for security. ... for every engagement that we have, we inform the cantonal police station that we are available for if something were to happen. So it happened ... we were called by the police because there were suspicious people who had made burglary attempts in the region of "Chênex", near "Geneva". We came with the drone and we were able to [apprehend] a person, etc. So it was an example of cooperation between the two entities, between the border guards and the cantonal police. (Head of planning and drone engagement, border guard, 23 September 2014).

The spaces used by the border guards may therefore be spaces in which multiple actors are located and carry out similar tasks. Like Fichet (2009), we have observed that the border guards perform tasks that were previously entrusted mainly to the police (or even the army). They no longer focus solely on mobilities that gravitate close to the border space but rather monitor the entire population. Thanks to the use of a "new" aerial technology, which is more mobile and flexible, professional boundaries are blurring, skill sets are converging and the spaces which must be secured are being shared. The example of airspace security during Euro 2008 in Switzerland bears witness to this fact, as the ADS-95 was used to fly over Basel, Bern and Zurich. The use of drones therefore redefines the relationships between actors from the various spheres, echoing the writings of Raffestin (1986), who suggests that relationships are vectors of exchange and collaboration.

Consequently, the entire drone system, including the security actors that are directly and indirectly involved, is becoming more flexible in order to adapt to the mission. While previously, certain interventions typically came under the aegis of a specific security actor (communal or cantonal police, border guards, army, private actors), the use of drones is decreasing this trend and favouring a convergent collaborative process. Territorial and professional limits are thus becoming less rigid, more flexible and are being constantly redefined. We might therefore ask ourselves to what extent these limits will diminish or be reinforced in the future, as the arrival of the new drones presupposes a new technological flexibil- ity that will give rise to new sociospatial, collaborative and monitoring practices.

\section{Conclusion: towards a redefinition of border space relationships}

In this paper, we first sought to demonstrate that the Swiss military drone system appears to be a "new" mediator, offering access to new knowledge of both airspace and land space during drone engagements. Observing, locating and tracking individuals and objects around the border and within the territory are "new" possibilities for the border guards, whose main purpose is to monitor the mobilities circulating in areas targeted by the mission.

Initially, we demonstrated that the use of the ADS-95 supports the acquisition of "new" data both in real time and remotely. The use of drones is therefore added to the preexisting security tools, such as computer databases and information from other national security actors. They combine with and complement parallel security measures to monitor a society in motion (Scherrer, 2013; Côté-Boucher, 2010) which we try to manage and filter (Klauser, 2008, 2013) in order to prevent potential dangers. We then deemed it important to put the potential of this technology into perspective by qualifying the favourable opinions of our interviewees. From our point of view, the drone system limits the knowledge transmitted, produces inequalities in surveillance and provides incomplete data that require verification of the observed information.

Secondly, with regard to the mobile and flexible nature of the drone, we aimed to examine the changes that this will give rise to in terms of surveillance and identification controls and also in terms of relationships with space. Our observations show that the latter relationships are being constantly modulated and renegotiated through a more mobile, flexible and bespoke surveillance system. This surveillance thus adapts itself to the needs of the mission, whether on the border line or within the territory (Raffestin, 1986). This has two consequences. On the one hand, we suggest that the border guards' relationships with the border area are reinforced by the new knowledge they acquire from the entire border space. While some places were inaccessible and/or too remote (both visually and physically), they are now observable and reachable, even remotely. The surveillance areas have thus expanded while the accuracy of the information collected has increased. The drone engagements therefore allow the user to go beyond fixed surveillance and identification controls which are restricted to the border line (e.g. customs posts). It expands in a more irregular way and redefines itself at the will of its users. On the other hand, we believe that the drone engagements weaken the relationships with the border space, because their action zones are expanded. The use of drones thus facilitates surveillance which is detached from the border space, thus reducing their "anchor- 
ing" to this space. Thus, they no longer perform mere border surveillance, but rather surveillance throughout the whole Swiss territory. This includes both residential and industrial, urban and rural areas, in which the border guards operate and develop new relationships with other security actors within the territory. Consequently, whether they are reinforced or weakened, relationships with the border space are redefined through the use of a technology which is ever more mobile and more flexible and which gives rise to a (re)appropriation of the (new) spaces monitored by the border guards.

This paper thus addresses a fundamental problem with respect to the surveillance and identification controls practised by certain Swiss public authorities whose mission is to secure the national territory. Focusing on security issues, this study is all the more interesting in that it suggests the need to pursue new research regarding the militarisation of urban space and certain actors such as the border guards or police (Graham, 2011; Weber, 2011), the integration of new technology into pre-existing security systems (Lemieux and Dupont, 2005) or the sociospatial implications of the distancing of digital aerial technologies (Coeckelbergh, 2013; Adey et al., 2011). Thus, beyond the scientific questions under discussion, this paper suggests that modern states rethink their enthusiasm and interest in acquiring and using ever more sophisticated techniques to circumscribe uncertainty and risk. In this quest for more efficient technology to lead to the illusory "zero risk", there are many security, sociopolitical and even ethical issues, which are thus at the very heart of the evolutions that are taking place within contemporary society.

\section{Data availability}

Confidential qualitative interviews were conducted by the author. Authorization for publication is required from interviewed military officers.

Competing interests. The author declares that she has no conflict of interest.

Acknowledgements. Many thanks to Hannah Juby from Express Language (www.expresslanguage.co.uk) for translating this paper.

Edited by: B. Korf

Reviewed by: two anonymous referees

\section{References}

Aas, K. F.: Getting ahead of the game: border technologies and the changing space of governance, Global Surveillance and Policing, 194-214, 2005.

Adey, P.: Air/atmospheres of the megacity, Theor. Cult. Soc., 30, 291-308, 2013.
Adey, P., Whitehead, M., and Williams, A. J.: Introduction: Airtarget distance, reach and the politics of verticality, Theor. Cult Soc., 28, 173-187, 2011.

Amilhat-Szary, A.-L.: Qu'est-ce qu'une frontière aujourd'hui?, Presses universitaires de France, 2015.

Amoore, L.: Biometric borders: Governing mobilities in the war on terror, Polit. Geogr., 25, 336-351, 2006.

Amoore, L., Marmura, S., and Salter, M. B.: Smart borders and mobilities: spaces, zones, enclosures, Surveillance \& Society, 5, 96101, 2002.

Andrejevic, M.: Ubiquitous surveillance, Routledge handbook of surveillance studies, 91-98, 2012.

Aubout, M.: Le milieu aérien, acteur et objet du renseignement, Hérodote, 81-90, 2011.

Baconnet, A.: Au pays des drones, Outre-Terre, 245-248, 2014.

Bauman, Z. and Lyon, D.: Liquid surveillance: A conversation, John Wiley \& Sons, 2013.

Bigo, D.: Pierre Bourdieu and international relations: Power of practices, practices of power, International Political Sociology, 5, 225-258, 2011.

Blackmore, T.: Dead slow: unmanned aerial vehicles loitering in battlespace, B. Sci. Technol. Soc., 25, 195-214, 2005.

Blot, F.: Les rapports entre société et eau: territorialité et/ou technicité, Cybergeo: Revue européenne de géographie/European journal of geography, 1-3, 2005.

Bonditti, P.: Biométrie et maîtrise des flux: vers une "géotechnopolis du vivant-en-mobilité"?, Cultures \& Conflits, 58, 131-154, 2005.

Bonditti, P.: L'Europe: tracer les individus, effacer les frontières, 2011.

Ceyhan, A.: Sécurité, frontières et surveillance aux Etats-Unis après le 11 septembre 2001, Cultures \& Conflits, 53, 113-145, 2004.

Ceyhan, A.: Enjeux d'identification et de surveillance à l'heure de la biométrie, Cultures \& Conflits, 4, 33-47, 2006.

Coeckelbergh, M.: Drones, information technology, and distance: mapping the moral epistemology of remote fighting, Ethics and information technology, 15, 87-98, 2013.

Côté-Boucher, K.: Interdictions à la mobilité, identités autorisées et échange de renseignements: la frontière intelligente vue du Canada, Mobilités sous surveillance, 99-116, 2010.

Crandall, J.: Unmanned: Embedded reporters, predator drones and armed perception, CTheory, 4-9/2003, 2015.

Deboosere, P. and Dessouroux, C.: Le contrôle de l'espace et de ses usage (r) s: avancées technologiques et défis sociaux, Espace populations sociétés, Space populations societies, 3-11, 2013.

Elden, S.: Secure the volume: Vertical geopolitics and the depth of power, Polit. Geogr., 34, 35-51, 2013.

Feldman, K. P.: Empire's Verticality: The Af/Pak Frontier, Visual Culture, and Racialization from Above, comparative american studies, 9, 325-341, 2011.

Fichet, B.: Les droits des étrangers et les nouveaux gardes frontières, Revue des sciences sociales, 2009.

Finn, R. L. and Wright, D.: Unmanned aircraft systems: Surveillance, ethics and privacy in civil applications, Computer Law \& Security Review, 28, 184-194, 2012.

Graham, S.: Cities as battlespace: the new military urbanism, City, 13, 383-402, 2009.

Graham, S.: Cities under siege: The new military urbanism, Verso Books, 2011. 
Graham, S. and Hewitt, L.: Getting off the ground On the politics of urban verticality, Prog. Hum. Geog., 37, 72-92, 2013.

Graham, S. and Wood, D.: Digitizing surveillance: categorization, space, inequality, Crit. Soc. Policy, 23, 227-248, 2003.

Gregory, D.: The everywhere war, Geogr. J., 177, 238-250, 2011.

Heilmann, E.: Le marché de la vidéosurveillance. Du maintien de l'ordre public à la gestion des (dés) ordres privés, 2005.

Heyman, J.: The state and mobile people at the US-Mexico border, Class, contention, and a world in motion, 8, 58, 2010.

Jensen, O. B.: Drone city - power, design and aerial mobility in the age of "smart cities", Geogr. Helv., 71, 67-75, doi:10.5194/gh71-67-2016, 2016.

Kennedy, G.: Drones: legitimacy and anti-Americanism, Parameters, 42, 25, 2012.

Kitchin, R. and Dodge, M.: Code/space: Software and everyday life, Mit Press, 2011.

Klauser, F. R.: Difficulties in revitalizing public space by CCTV: Street prostitution surveillance in the Swiss city of Olten, Eur. Urban Reg. Stud., 14, 337-348, 2007.

Klauser, F.: Spatial articulations of surveillance at the FIFA World Cup 2006TM in Germany, Technologies of insecurity, 61-80, 2008.

Klauser, F. R.: Thinking through territoriality: introducing Claude Raffestin to Anglophone sociospatial theory, Environ. Plann. D, 30, 106-120, 2012a.

Klauser, F. R.: Interpretative Flexibility of the Event-City: Security, Branding and Urban Entrepreneurialism at the European Football Championships 2008, Int. J. Urban Regional, 36, 1039-1052, 2012b.

Klauser, F.: Spatialities of security and surveillance: Managing spaces, separations and circulations at sport mega events, Geoforum, 49, 289-298, 2013.

Klauser, F. and Pedrozo, S.: Power and space in the drone age: a literature review and politico-geographical research agenda, Geogr. Helv., 70, 285-293, doi:10.5194/gh-70-285-2015, 2015.

Klauser, F., November, V., and Ruegg, J.: Surveillance et vigilance dans la sécurité routière: L'exemple de l'autoroute de contournement à Genève, PUSE, 2006.

Kurgan, L.: Close up at a distance: Mapping, technology, and politics, MIT Press, 2013.

Lambeth, B. S.: Air Force-Navy Integration in Strike Warfare, Naval War College Review, 61, 26, 2008.

Lemieux, F. and Dupont, B.: La militarisation des apparelis policiers, Presses Université Laval, 2005.

Loudiyi, S., Angeon, V., and Lardon, S.: Capital social et développement territorial. Quel impact spatial des relations sociales, Espaces et Sociétés, 2004.

Lussault, M. and Lévy, J.: Dictionnaire de la géographie et de l'espace des sociétés, 2003.

Lyon, D.: The border is everywhere: ID cards, surveillance and the other, Global surveillance and policing: Borders, security, identity, 66-82, 2005.
Lyon, D.: Theorizing surveillance, Routledge, 2006.

Lyon, D.: Surveillance studies: An overview, Polity, 2007.

Mitchell, C. M.: Killing at a Distance in a Post-Panoptic Society, Virginia Tech, 2015.

Muggah, R. and Diniz, G.: Securing the border, Strategic Paper, 5, 1-29, 2013.

Pedrozo, S.: Visual representation of the location of the actors, Plan drafted by the border guards, 2016a.

Pedrozo, S.: Reproduction of a "drone engagement" map, $2016 \mathrm{~b}$.

Philippens, H.: Drones and deterrence: How robotics will impact strategic stability, Royal United Services Insitute, 1-12, 2013.

Raffestin, C.: Pour une géographie du pouvoir, Libraires techniques, 1980.

Raffestin, C.: Remarques sur les notions d'espace, de territoire et de territorialité, Espaces et sociétés, 167-171, 1982.

Raffestin, C.: La territorialité: miroir des discordances entre tradition et modernité, Revue de l'Institut de Sociologie, 437-447, 1984.

Raffestin, C.: Eléments pour une théorie de la frontière, Diogène, 34, 3-21, 1986.

Raffestin, C.: Une nouvelle géographie de la Suisse: pour qui, pour quoi?, 1990.

Raffestin, C. and Bresso, M.: Tradition, modernité, territorialité, Cahiers de géographie du Québec, 26, 185-198, 1982.

Scherrer, A.: Lutte antiterroriste et surveillance du mouvement des personnes, Criminologie, 46, 15-31, 2013.

Szary, A.-L. A. and Giraut, F.: Borderities: The politics of contemporary mobile borders, in: Borderities and the Politics of Contemporary Mobile Borders, Springer, 1-19, 2015.

Wall, T. and Monahan, T.: Surveillance and violence from afar: The politics of drones and liminal security-scapes, Theor. Criminol., 15, 239-254, 2011.

Weber, J.: Techno-Security, Risk and the Militarization of Every Day Life, 168-173, 2011.

Wheeler, W. T.: A Final Word on Drones and Reaper, Center for Defense Information, 1-19, 2012.

Widmer, S., Pedrozo, S., and Klauser, F. R.: Mobilités et gestion des flux à l'ère numérique, Éditions Alphil-Presses Universitaires Suisses, 2014.

Williams, B.: Ethics and the Limits of Philosophy, Taylor \& Francis, 2011.

Wood, D. and Graham, S.: Permeable boundaries in the softwaresorted society: Surveillance and the differentiation of mobility, Mobile technologies of the city, 177-191, 2006.

Younsi, A.: Les drones "MALE" en France: intermédiaires ou médiateurs?, Réseaux, 185-215, 2015.

Zubeldia, O.: Histoire des drones, Perrin, 2012.

Zureik, E.: Colonialism, surveillance, and population control, Surveillance and control in Israel/Palestine: Population, territory and power, 3-46, 2011. 